\title{
REVIEW
}

\section{The national strategy for sexual health and HIV: implications for genitourinary medicine}

\section{W Adler, P French, A McNab, C Smith, S Wellsteed}

The first ever national strategy for sexual health and HIV in England was published in July 2001 and proposes a comprehensive and holistic model for dealing with an increasing public health problem. The strategy covers the issues of prevention, service provision, commissioning of services, and the necessary requirements to support change. This paper concentrates on service issues and developments in relation to genitourinary medicine/HIV services, and outlines a model for providing these which attempts to do so around patients' needs, delivered through comprehensive and interlinked local networks of services.
See end of article for authors' affiliations

Correspondence to: $M$ Adler, Department of Sexually Transmitted Diseases, Royal Free and University College Medical School, The Mortimer Market Centre, Off Capper Street, London

WC1E 6AU, UK madler@gum.ucl.ac.uk

Accepted for publication 20 February 2002
T he first ever national strategy for sexual health and HIV for England was published at the end of July 2001 and proposes a comprehensive and holistic model. ${ }^{1}$ The key objectives of the strategy are to ensure that everyone has better access to information on sexual health and to make services more available and accessible to all those who require them, at all ages. A comprehensive modern sexual health service needs to incorporate the areas of contraception and abortion, diagnosis, treatment and prevention of STIs and HIV, and services for psychosexual problems/sexual dysfunction. This paper concentrates on service issues and developments in relation to genitourinary medicine (GUM)/HIV services. These specialist services are at the heart of the strategy and should offer high quality leadership in partnership with other providers.

\section{A NEW MODEL OF WORKING}

The strategy outlines a model for providing services which attempts to do so around patients' needs delivered through comprehensive and interlinked local networks of services. Three levels of service provision are outlined; level 1 being all primary care teams, level 2 suggests the development within primary care trusts (PCTs) of primary care teams with a special interest in sexual health and, finally, level 3 services, the specialist services such as GUM, abortion, and community family planning. Examples are given of the types of services that could be offered at each level (table 1). The level 3 services currently provide many elements of service at levels 1 and 2 and will continue to do so.

Patients' first point of contact is often their general practitioners, who can assess their needs and decide whether to treat them there and then or refer them to more specialist services. The more specialist service could be found at level 2 where a primary care team would have developed a particular expertise in this area of medicine. It is realised that not all elements of general sexual health services can be provided easily or economically by every primary care team, and therefore the development of such teams with a special interest would allow for such services to be offered to people registered with other practices. Those working at levels 1 and 2 could clearly refer patients to specialised services (level 3). In reality, large numbers of patients will bypass levels 1 and 2 and continue to refer themselves straight to departments of genitourinary medicine, contraception services, etc.

\section{THE CONTRIBUTION OF}

\section{GENITOURINARY MEDICINE}

Genitourinary medicine will have a pivotal role in the implementation of the strategy, both by service delivery within clinics (level 3) but, as importantly, by being the specialist resource within a

Table 1 Elements of sexual health care that should be available at different levels

Level 1 (every general practice)

Sexual history and risk assessment

STI testing for women

Assessment and referral of men with STI symptoms

HIV testing and counselling

Hepatitis B immunisation

Provision of oral hormonal contraception Information about choice of full range of contraceptive methods and where available Cervical cytology screening and referral Pregnancy testing and referral

Level 2 (primary care teams with a special interest) Testing and treating sexually transmitted infections Partner notification

IUD and implant insertion

Management of psychosexual problems Vasectomy surgery

Level 3 (specialist services)

Outreach for STI prevention/contraception

Specialised STI management/partner notification Specialist HIV treatment and care

Highly specialised contraception

TOP services

Local coordination and back up for sexual assault Psychosexual/sexual dysfunction services

Make sure local guidelines and framework for monitoring and improving practice are in place Support clinical governance requirements at all levels

Provide professional training, designing and updating care pathways and developing new services 
locality. GUM services must continue to be delivered on an open access basis. The strategy recognises that there are current problems and is committed to increasing access and reducing waiting times, particularly for urgent appointments, and it makes mention of the need for attractive, comfortable, accessible and available clinics. The condition and opening hours of clinics vary throughout the country and there is a need to modernise services. As well as identifying the need for modernisation, the strategy recognises the need to examine the implications of its recommendations for workforce numbers and skill mix, particularly how multiprofessional teams "can best provide patient-centred services across traditional services and professional boundaries."

The Department of Health (DoH) is committed to developing the role and increasing the number of health advisers within genitourinary medicine. Even though they will be based within departments of genitourinary medicine it is envisaged that they will also develop an outreach and community focus. For example, health advisers should work in close collaboration with primary care teams and assist them, if necessary and required, to carry out partner notification for their patients. Likewise, nurses are a valuable resource for providing sexual health services. It is hoped that both within primary care and specialist services such as genitourinary medicine and contraception, nurses will have an expanded and extended role. There is evidence within genitourinary medicine that nurses can successfully and efficiently extend their role and be involved in comprehensive patient care and the strategy indicates that nurses will have this expanded role at level 3 as specialist and consultants. ${ }^{2}$

Even though the focus of the work of GUM physicians is within their clinic, they will need to have a wider and more central role in STI/HIV control. They should take on responsibility for outreach services for STIs and support health education initiatives in the community-for example in schools, colleges, and prisons.

The specialists will be essential in ensuring that local guidelines are established and that frameworks exist for monitoring and improving practice. Even though the GUM physicians will take a lead in this, it must be done in partnership with all those working at level 1 and, particularly, level 2. "At the specialist level ...clinical teams will be responsible for supporting the clinical governance requirements at all levels, providing professional training, designing and updating care pathways and developing new services."1 Thus, genitourinary medicine will be central to the strategy by offering expert clinical advice, working closely with colleagues in the community, rolling out training and being integral in the development of care pathways, new services, and establishment of maintenance and standards. Ultimately, the service model described within the strategy should see that consistent and coordinated services are delivered across primary care and specialist services.

Managed service networks are being developed between specialist services around HIV management and are becoming increasingly accepted. This concept should now be extended to all sexual health provision. Thus, the meshing together of all levels within a locality will be through service networks which focus on cooperation and integration to meet local needs of the community. Such networks should also mean cooperation and collaboration between specialist services over a wider area. Each part and level of this network will have explicit responsibilities, and clear referral pathways between the levels will need to be recognised and established.

The network approach described will require the development of shared standards of care between providers, which will need to be defined, implemented and monitored locally, and incorporated into the clinical governance processes. Providers and commissioners will also need to develop standards across the local network both for clinical services and information. Within the strategy it is suggested that clinical services standards could cover open access, referral between services (care pathways), the availability of a full range of clinically effective services, staff training, support, continuing professional development and lifelong learning, and service monitoring, audit, and evaluation. Standards for information for service users might cover information about the choice of services including which elements of clinical care are available, where and when services are provided, and pathways between them, and access criteria for such services.

\section{OTHER MODELS OF SERVICE DELIVERY}

During the development of the strategy a number of consultations were carried out. In particular, those with young people indicated that they wished to have one stop shop sexual health services, and there is a commitment within the strategy to evaluate three such models across the country. It will also be important to evaluate the benefits of the integrated services outlined in the strategy; for example, the concept of primary care teams with a special interest needs to be examined more closely in line with the NHS plan and Royal College of General Practitioners initiatives. ${ }^{34}$

The two chlamydia screening pilots carried out in the Wirral and Portsmouth indicate that this is an acceptable and appropriate approach. ${ }^{5}$ As a result, chlamydia screening will be rolled out from 2002, but to start with only to selected groups such as young women attending GUM clinics, seeking termination of pregnancy, or having their first cervical smear. This will result in an increase in workload within departments of genitourinary medicine. In addition, since testing will be carried out in non-GUM sites, there may well be onward referral from these for comprehensive STD screening, partner notification, etc.

There is increasing demand for psychosexual and dysfunction services within the NHS and these are currently given by a wide range of providers with variable training and standards. The strategy is committed to developing consistent standards of care and training to ensure that patients are managed or referred appropriately.

\section{HIV TESTING/HEPATITIS B VACCINATION}

It is of some concern that approximately one third of individuals who are HIV positive do not know their status. The strategy hopes to improve access to testing by promoting, supporting, and encouraging HIV testing in primary care and other general medical settings. It is of course recognised that departments of genitourinary medicine have always offered HIV testing, and the strategy will now require all departments to offer such testing to all attenders on first screening for STIs and also to offer hepatitis $\mathrm{B}$ vaccine to homosexual men, injecting drug users, and commercial sex workers. The targets for reducing undiagnosed HIV and increasing the uptake of hepatitis B vaccine are indicated in table 2.

HIV testing and hepatitis B vaccination are not the prerogative of the specialist. To improve coverage of both of these initiatives, primary care will be required to play a more important and proactive part in offering testing and vaccination.

\section{HIV TREATMENT}

The care and treatment of individuals with HIV infection is becoming more complex and specialised. As indicated earlier, the strategy is supportive of the concept of managed networks and expects all HIV practitioners to work within such networks. The BMA Foundation for AIDS developed national guidelines for HIV services in $1999 .{ }^{6}$ These will now need to be updated and national HIV standards will be developed by 2002 .

Managed service networks for both sexual health and HIV services requires shared standards of care to be developed between the various providers and to be monitored locally and become part of the clinical governance process. 


\section{Table 2 Targets \\ - To reduce by $25 \%$ the number of newly acquired HIV and gonorrhoea infections by the end of 2007 \\ - By the end of 2004, all GUM clinic attendees should be offered an HIV test on their first screening for sexually transmitted infections (and subsequently according to risk) with a view to: \\ - increasing the uptake of the test to those offered it to $40 \%$ by the end of 2004 and to $60 \%$ by the end of 2007 \\ - reducing by $50 \%$ the number of previously undiagnosed HIV infected people attending GUM clinics who remain unaware of their infection after their visit by the end of 2007 \\ - By the end of 2003, all homosexual and bisexual men attending GUM clinics should be offered hepatitis B immunisation at their first visit \\ - Expected uptake of the first dose of the vaccine, in those not previously immunised, to reach $80 \%$ by the end of 2004 and $90 \%$ by the end of 2006 \\ - Expected uptake of the three doses of vaccine, in those not previously immunised, within one of the recommended regimens to reach $50 \%$ by the end of 2004 and $70 \%$ by the end of 2006}

Table 3 Principles of effective commissioning of sexual health and HIV services

- Establish a local multiagency group (including local stakeholders and commissioning organisations), identify a lead commissioner, build on existing arrangements

- Ensure a sexual health and HIV plan is specified in the HIMP

- Work to reduce inequalities by targeting resources to high need groups

- Understanding local needs and identifying priority population groups

- Work in partnership with the range of stakeholders

- Use a range of mechanisms to ensure the diversity of user views are reflected in planning and monitoring

- Set and monitor performance indicators in line with national targets

The increase in newly diagnosed HIV/STIs in homosexual men $^{7-9}$ and continuing unsafe sex practices in HIV positive individuals needs addressing, and the strategy makes reference to the importance of HIV positive individuals having good sexual health promotion and sexual health care which would include STI screening. All too often, this issue is forgotten when the concentration is on HIV therapy and management.

\section{COMMISSIONING}

The commissioning of services will be vital for the effective implementation of the strategy and the DoH will publish a good practice "toolkit" to guide this across all three levels of care. From April 2002, PCTs will be in a position to commission sexual health services (genitourinary medicine, community family planning, and HIV prevention). Guidance to PCTs makes it clear that these three elements of sexual health have to be commissioned together and that within any locality it will not be possible to commission only one or two out of the three elements. It is recognised that specialist services for HIV treatment and care need to be commissioned differently, as specialist services. Commissioning and local service development will be based on an assessment of local need and identifying gaps in services. Certain principles should be applied by those undertaking commissioning (table 3).

\section{INFORMATION AND DATA COLLECTION}

Adequate and timely information and data collection systems are essential to monitor the strategy and national and local interventions. Work on expanding these systems will reap benefits in our ability to be able to ascertain epidemiological trends, service utilisation and act as a clinical governance tool. Even though information systems in England provide a range of data relevant to sexual health and HIV, there are significant gaps. A review will be set up to examine these and additional needs such as how to improve the coordination of data collection, capture information from new services such as NHS walk-in centres and, finally, improve information on behaviour and attitudes.

\section{DISCUSSION}

The strategy will modernise our approach to sexual health and offers a vision of common aims, working practices, standards, and cooperation. Unlike many countries in the world, specialist services for STIs exist. The strategy will attempt to bring these specialist services into partnership with other providers of care skilled up to provide better sexual health. This should allow for more effective control of sexually transmitted infections within the community. Hopefully, this will also allow for a stronger voice in the argument for the importance of this area of medicine and public health and adequate resourcing. Those working in genitourinary medicine are central to the delivery and success of the strategy. However, there are very special issues and pressures in relation to increased workload and poor estate that will need to be tackled,

The survey of GUM clinic access carried out in the year 2000 indicated delays for both urgent and routine problems. Repeated in 2001, there had been further deterioration. ${ }^{10}{ }^{11}$ For example, $34 \%$ of clinics were now appointments only, $39 \%$ of clinics were unable to see urgent cases within 24 hours, $68 \%$ had routine appointment delays of 1 week or more, $77 \%$ reported turning patients away, and finally $81 \%$ indicated that waiting time had increased during the past year. These delays in access will militate against effective public health control of STIs. The doubling of attendances at departments of GUM in the past decade has not been matched by consultant expansion, which has only risen by $30 \%$ over the same time. The Royal College of Physicians GUM Liaison Committee has made recommendations on consultant expansion based on one consultant per 113000 of the population. This would require an increase of 93\% (192 WTEs) in England. If phased over 5 years this would require 35 new posts per year.

While it is true that the Monks report of 1988 and the HIV epidemic resulted in additional resources for genitourinary medicine, and some modernisation, this has not kept up with demand. ${ }^{12}$ Thirty per cent of GUM clinics operate 3 days a week or less. In the spring of 2001 the Association for Genitourinary Medicine (AGUM) and the Medical Society for the Study of Venereal Diseases (MSSVD) carried out a survey to investigate the need for improvements to clinic infrastructure, and suggested a modernisation programme spread over the next 6 years. ${ }^{13}$ This programme was a mixture of refurbishment and rebuilding at a total cost of $£ 248$ million. Additionally, attention has been drawn to the inadequate information technology in clinics which, if corrected and modernised, would cost a further $£ 28.5$ million.

The strategy recognises the issues of staffing and estate and is committed to reviewing these. However, it must be realised that only $£ 47.5$ million have been allocated to the strategy over the next 2 years. Comment has been made that this "is manifestly

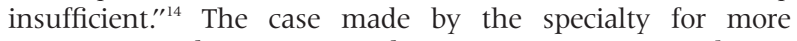
resources, modernisation, and expansion are strong, but it would be naive to suppose that this argument will be easily won. The strategy offers the vision and ammunition for all within genitourinary medicine to argue their case, both at a national and local level and as a result build a truly modern service at the heart of a holistic and comprehensive approach to sexual health.

\section{ACKNOWLEDGEMENTS}

The authors are grateful to all members of the Sexual Health and HIV Strategy for their work as well as those who made contributions to the various subgroups and working groups. 
Work on the targets was led from within the Department by the EOR Division (Jeremy Townshend and Robert Anderson). We are also particularly grateful to the contribution made by CDSC in the provision of data and work on the targets.

Funding: Department of Health

Conflict of interest: None.

\section{CONTRIBUTORS}

MA was seconded to the Department of Health to take a lead in the development of the strategy and chaired the steering group; PF and CS were both members of the steering group and jointly chaired a group looking at service issues; AM was the lead civil servant within the Department of Health leading on the strategy; SW was particularly responsible for the chlamydia screening project and general input to the development of the strategy. All of the above contributed in their various roles to the writing of the paper.

\section{Authors' affiliations}

M W Adler, Department of Sexually Transmitted Diseases, Royal Free and University College Medical School, The Mortimer Market Centre, Off Capper Street, London WC1E 6AU, UK

P French, Department of Genitourinary Medicine, Camden and Islington Community Health Services NHS Trust, The Mortimer Market Centre, Off Capper Street, London WC1E 6AU, UK

A McNab, S Wellsteed, Department of Health, Skipton House, 80 London Road, London SE 1 6LH, UK

C Smith, Parkside Health NHS Trust, Charles' Hospital, Exmoor Street London W10 5SH, UK

\section{REFERENCES}

1 Department of Health. The national strategy for sexual health and HIV. London: Department of Health, 2001
2 Miles K, Power R, Mercey D et al. Nurse-led care in central London sexual health clinic: results of a randomised controlled study, patient satisfaction survey and economic analysis. Oral presentation/abstract 19, the Joint STDA/MSSVD STIs at the Millenium Conference, Baltimore USA, 3-6 May 2000.

3 Secretary of State for Health. The NHS plan. A plan for investment, a plan for reform. London: Stationery Office, 2000.

4 Royal Colleges of General Practitioners and Physicians. General practitioners with special clinical interests. London: RCGP, 2001.

5 Pimenta J, Catchpole M, Gray M, et al. Screening for genital chlamydia infection. BM 2000;321:629-31.

6 Centre for Research on Drugs and Health Behaviour/BMA Foundation for AIDS. Standards for NHS hospital HIV services. 1999.

7 Sigma Research. Vital statistics findings from the national gay men's sex survey 1999. July 2000.

8 Imrie J, Davis MD, Black S, et al. Meeting the sexual health needs of HIV-seropositive gay men is a pre-requisite to developing the next generation of prevention strategies. (Oral presentation) 14th Meeting of the International Society for Sexually Transmitted Diseases Research (ISSTDR) and International Congress of Sexually Transmitted Infections, Berlin, Germany, 24-27 June 2001

9 PHLS (England, Wales and Northern Ireland), DHSS +PS (Northern Ireland) and Scottish ISD Collaborative Group. Sexually transmitted infections in the UK-new episodes seen at genitourinary medicine clinics, 1995-2000. December 2001

10 Diuretic T, Catchpole M, Bingham J, et al. Genitourinary medicine services in the United Kingdom are failing to meet current demands. Int $J$ STDs AIDS 2001:12:571-2

11 O'Mahony C, Carne C, Kell P, et al. GUM Clinic Access Report, July 2001, personal communication.

12 Monks Working Party. Report of the working group to examine workloads in GUM clinics, London. London: Department of Health, November 1988.

13 Medical Society for the Study of Venereal Diseases and Association for Genitourinary Medicine. Modernising genitourinary medicine services in England and Wales. Personal communication.

14 Kinghorn G. Sexual health and HIV strategy for England. BM 2001;323:243-4.

\section{NEW STI ONLINE SUBMISSION AND REVIEW SYSTEM}

I am pleased to inform authors and reviewers that as of 21 February 2002, STI will be using a new online submission and review system. Developed by Highwire Press (CA, USA), Bench>Press is a fully integrated electronic system which utilises the web to allow rapid and efficient submission of manuscripts. It also allows the peer review process to be conducted entirely online. The aim, apart from saving trees, is to speed up the frequently frustrating progress from submission to publication.

Authors can submit their manuscript in any standard word processing software. Standard graphic formats acceptable are: .jpg, .tiff, .gif, and eps. (nb. multipage powerpoint files are NOT acceptable). The text and graphic files are automatically converted to PDF for ease of distribution and reviewing purposes. Authors are asked to approve their submission before it formally enters the reviewing process. On approval by the authors, the submission is passed to the editor and/or reviewers via the web. All transactions are secure.

To access the system click on "SUBMIT YOUR MANUSCRIPT HERE" on the STI homepage: http://www.sextransinf.com/ or you can access Bench>Press directly at http://submit-sti.bmijournals.com/.

We are very excited with this new development and I would encourage authors and reviewers to use the online system where possible. It really is simple to use and should be a big improvement on the current peer review process. Full instructions can be found on Bench>Press and STI online. Please contact Natalie Davies, Project Manager, ndavies@bmigroup.com for further information.

\section{PRE-REGISTER WITH THE SYSTEM}

We would be grateful if all Sexually Transmitted Infections authors and reviewers pre-registered with the system. This will give you the opportunity to update your contact and expertise data, allowing us to provide you with a more efficient service.

\section{Instructions for registering}

1. Enter http://submit-sti.bmijournals.com

2. Click on "Create a New Account" in the upper left hand side of the Bench $>$ Press homepage

3. Enter your email address in the space provided.

4. Choose a password for yourself and enter it in the spaces provided.

5. Complete the question of your choice to be used in the event you cannot remember your password at a later time.

6. Click on the "Save" button at the bottom of the screen.

7. Check the email account you registered under. An email will be sent to you with a verification number and URL.

8. Once you receive this verification number, click on the URL hyperlink and enter the verification number in the relevant field. This is for security reasons and to check that your account is not being used fraudulently.

9. Enter/amend your contact information, and update your expertise data. 